\title{
Comparison of blood loss between intra-articular and intra-venous administration of tranexamic acid in primary total knee arthroplasty
}

\author{
Muhammad Suhail Amin ${ }^{1}$, Muhammad Khurram Habib ${ }^{2, *}$, and Aziz Ur Rehman ${ }^{3}$ \\ 1 Professor Orthopedic, CMH Hospital Rawalpindi and CMH Lahore Orthopedic ward, CMH Hospital Rawalpindi, Pakistan \\ 2 Assistant Professor Orthopedics, DHQ Hospital Faisalabad, Clinical Fellow, CMH Lahore, DHQ Hospital Faisalabad Orthopedics ward, \\ Pakistan \\ ${ }^{3}$ Clinical fellow CMH Hospital Rawalpindi and CMH Lahore, Pakistan
}

Received 30 October 2019, Accepted 27 May 2020, Published online 17 June 2020

\begin{abstract}
Objective: To compare the blood loss between intra-articular and intra-venous administration of tranexamic acid (TXA) in patients undergoing primary total knee arthroplasty. Design of study: It was a randomized controlled trial. Study duration and settings: This study was carried out at the Orthopedic Departments of Combined Military Hospital Lahore and Rawalpindi from Jan 2016 to March 2018. Methodology: Patients of both the genders were involved this study who had age in the rage of 40-80 years undergoing primary unilateral total knee arthroplasty for degenerative conditions like osteoarthritis and rheumatoid arthritis. These patients were randomly divided into two treatment groups. Patients in IA group received intra-articular tranexamic acid while those in IV group received intravenous tranexamic acid. From all the patients, a written signed consent was taken. Findings: Females were predominant with male-to-female ratio of 1:3.7. The mean age of the patients was $67.3 \pm 8.2$ years while the mean BMI was $30.9 \pm 2.9 \mathrm{Kg} / \mathrm{m}^{2}$. Majority $(n=191,95.5 \%)$ of the patients had osteoarthritis while remaining $9(4.5 \%)$ patients had rheumatoid arthritis. There was no statistically significant difference between intra-articular and intravenous administration of tranexamic acid in terms of mean post-operative hemoglobin $(9.93 \pm 1.14$ vs. $9.87 \pm 1.26 \mathrm{~g} / \mathrm{dL} ; p$-value $=0.724)$, mean post-operative hematocrit $(34.8 \pm 1.66$ vs. $34.73 \pm 1.27 \% ; p$-value $=0.594)$, and mean fall in hemoglobin $(2.27 \pm 0.34$ vs. $2.25 \pm 0.30 \mathrm{~g} / \mathrm{dL} ; p$-value $=0.587)$ and hematocrit $(2.34 \pm 0.94$ vs. $2.46 \pm 0.28 \%$; $p$-value $=0.216$ ). Conclusion: Intra-articular administration of tranexamic acid was found to be as effective and safe as intra-venous administration in reducing blood loss in primary total knee arthroplasty. Due to convenience, the use of intra-articular administration of tranexamic acid after primary TKA may be considered in future practice.
\end{abstract}

Key words: Primary Total Knee Arthroplasty, Tranexamic Acid, Intra-articular, Blood Loss.

\section{Introduction}

Despite that advancements in fixation and design techniques of implants have substantially increased functional results and survival rates of total knee arthroplasty (TKA), during the procedure loss of blood is a major concern that is perioperatively estimated to be $850-1600 \mathrm{~mL}$ [1]. During TKA, Patient's recovery may be affected negatively by blood loss. Allogenic blood transfusion may be needed on the basis of amount of blood lost during the procedure [2]. Moreover, high post-operative infections are also associated with this procedure [3], measures which can reduce operative loss of blood and

\footnotetext{
*Corresponding author: khurramhabibortho@gmail.com
}

subsequent necessitating blood transfusion have always been adored and a hot focus of medical research [2].

From reducing operative blood loss, promising results have been given by tranexamic acid (TXA) among the various techniques used, till now [4]. Being synthetic amino acid, tranexamic acid functions by competitive inhibition of plasminogen conversion into plasmin, thus promoting clot stabilization $[4,5]$. Followed by total knee arthroplasty, tranexamic acid has got identity as effective antifibrinolytic helpful in decreasing blood loss and transfusion risks. Moreover, it has not been associated with increased thromboembolic complications [6-28].

Surgeons may choose to administer tranexamic acid intravenously, topically, or orally [6]. Though, in total knee arthroplasty settings involving tranexamic acid, majority of 
the studies have focused on the intravenous route [6-21], topical spraying of TXA has been proved to be equally efficacious while being safer as far as post-operative problems like DVT are concerned [6-25]. The existing evidence on the efficacy of this topical application contained controversy where some studies claimed no difference between IV and IA routes in terms of blood loss [6-20], other showed significant difference and advocated intra-articular application [21-24] while still others reported intravenous route to be better and associated with significantly lower operative blood loss [25-28]. A major limitation to these studies was limited sample size of less than $30-50$ cases. Moreover, this study has also been necessitated by non-availability of locally published such material.

\section{Material and methods}

The present study was RCT (randomized controlled trial) carried out at the Orthopedic Departments of Combined Military Hospital Lahore and Rawalpindi from Jan 2016 to March 2018. Each group was comprised of 100 cases in this study having 200 cases sample size calculated with $95 \%$ significance level and $80 \%$ power of test considering expected mean postoperative hemoglobin to be $11.0 \pm 0.67 \mathrm{~g} / \mathrm{dL}$ in patients with intravenous and $10.6 \pm 1.26 \mathrm{~g} / \mathrm{dL}$ in patients with intra-articular tranexamic acid [28]. In this study, patients had age between 40 and 80 years belonging to both the genders suffering from advanced degenerative disease of knee planned for unilateral total knee replacement (TKR). However, patients with complex and revision complex knee arthroplasty, single stage bilateral total knee replacement, and unicompartmental knee arthroplasty were excluded from the study. By random allocation of these patients, two equal-sized treatment groups were made. Patients in IA group received $2 \mathrm{~g}$ of TXA in $20 \mathrm{~mL}$ solution injected by syringe into the joint after the prosthesis was inserted and cemented and the entire operative field was thoroughly rinsed and dried, no drain was placed and wound closed in layers before skin closure. Patients in IV group received intravenous dose of $1 \mathrm{~g}$ TXA administered 5-10 min before the pneumatic tourniquet was inflated [29].

This procedure was performed by a senior surgeon through standardized techniques. Under a high thigh tourniquet, a medial parapatellar and middle line incision approach was used during all the operative procedures. In all the cases, patella was resurfaced and tibial and femoral components were cemented. In all patients, PCL-sacrificing posterior stabilized knee prosthesis was used. They included: Vanguard ${ }^{\circledR}$ (Biomet), Genesis II $^{\circledR}$ (Smith \& Nephew) and PFC-Sigma (DePuy, Johnson \& Johnson) NexGen ${ }^{\circledR}$ (Zimmer, Ltd., Swindon, UK). The procedures were performed either under spinal anesthesia or general anesthesia always combined with an epidural. Before the closure of the wound, the tourniquet was deflated and hemostasis secured. No drain was placed in both groups. After layered closure and intra-articular injection in IA group, a compression bandage with the knee in extension was given, which stayed for about six hours post-operatively. Routine DVT (deep vein thrombosis) prophylaxis comprised of LMWH that was started $12 \mathrm{~h}$ pre-operatively and was continued for 30 days after the surgery.
Table 1. Demographic features of study groups.

\begin{tabular}{lccc}
\hline Characteristics & IA $n=100$ & IV $n=100$ & $P$ value \\
\hline Age (years) & $67.3 \pm 8.3$ & $67.3 \pm 8.1$ & 0.979 \\
Gender & & & \\
$\quad$ Male & $22(22.9 \%)$ & $21(21.0 \%)$ & 0.863 \\
$\quad$ Female & $78(78.0 \%)$ & $79(79.0 \%)$ & \\
BMI $\left(\mathrm{Kg} / \mathrm{m}^{2}\right)$ & $31.0 \pm 2.7$ & $30.7 \pm 3.1$ & 0.439 \\
Cause & & & \\
$\quad$ Osteoarthritis & $95(95.8 \%)$ & $96(94.1 \%)$ & 0.733 \\
$\quad$ Rheumatoid arthritis & $5(4.2 \%)$ & $4(5.9 \%)$ & \\
\hline
\end{tabular}

Chi-square test, Independent sample $t$-test, no significant difference was observed $(p>0.05)$.

Outcome variables were mean post-operative hemoglobin, mean post-operative hematocrit, and mean fall in hemoglobin and hematocrit all measured $24 \mathrm{~h}$ after surgery. Numerical variables like age, BMI, hematocrit, pre-operative and postoperative hemoglobin, and fall in hematocrit and hemoglobin have been described as mean $\pm \mathrm{SD}$. By taking $p$-value $\leq 0.05$ as statistically significant, for comparing mean of these various variables in the study group, independent sample test $t$-test was applied. Categorical variable like gender has been described as frequency and percentage. In order to minimize biasness, standard operative technique was used and a single surgeon performed all these procedures.

\section{Results}

Mean age of the patients was $67.3 \pm 8.2$ years with age ranging 48-80 years. The study group had $43(21.5 \%)$ male patients and $157(78.5 \%)$ female patients with a male-to-female ratio of 1:3.7. The BMI of the patients ranged from $24.0 \mathrm{Kg} / \mathrm{m}^{2}$ to $34.9 \mathrm{Kg} / \mathrm{m}^{2}$ with a mean of $30.9 \pm 2.9 \mathrm{Kg} / \mathrm{m}^{2}$. Majority ( $n=191,95.5 \%)$ of the patients had osteoarthritis while remaining $9(4.5 \%)$ patients had rheumatoid arthritis. The two study groups were homogenous in terms of mean age $(p$-value $=0.979)$, mean BMI $(p$-value $=0.439)$, mean preoperative hemoglobin $(p$-value $=0.606)$, mean pre-operative hematocrit $(p$-value $=0.953)$ and gender $(p$-value $=0.863)$ and etiologic $(p$-value $=0.733)$ groups distribution $($ Table 1$)$. In terms of mean post-operative hematocrit ( $p$-value $=0.594)$, post-operative hemoglobin $(p$-value $=0.724)$ and mean fall in hematocrit $(p$-value $=0.216)$ and hemoglobin $(p$-value $=0.587)$ no statistically significant difference was noted between IA and IV TXA. These findings have been summarized in Table 2.

\section{Discussion}

Different measures to reduce operative blood loss have been employed in orthopedic surgery to reduce the need for transfusion and hasten the patient's recovery in the post-operative period [2]. A frequently employed such technique is transfusion of autologous blood which also reduces the risk of infection, but it is expensive and not every center has the facility [2,3]. Another method for control of the perioperative blood loss is the application of anti-fibrinolytic agents including aprotinin, 
Table 2. Comparison of various outcome measures.

\begin{tabular}{lccc}
\hline Characteristics & IA $n=100$ & IV $n=100$ & $P$ value \\
\hline Pre-operative Data & & & \\
$\quad$ Pre-operative hemoglobin (g/dL) & $12.20 \pm 1.12$ & $12.12 \pm 1.20$ & 0.606 \\
$\quad$ Pre-operative hematocrit (\%) & $37.18 \pm 1.22$ & $37.19 \pm 1.20$ & \\
Post-operative data & & & \\
$\quad$ Post-operative hemoglobin (g/dL) & $9.93 \pm 1.14$ & $34.73 \pm 1.26$ & 0.953 \\
Post-operative hematocrit (\%) & $34.8 \pm 1.66$ & $2.25 \pm 0.30$ & 0.594 \\
Fall in hemoglobin (g/dL) & $2.27 \pm 0.34$ & $2.46 \pm 0.28$ & 0.587 \\
Fall in hematocrit (\%) & $2.34 \pm 0.94$ & & 0.216 \\
\hline
\end{tabular}

Independent sample $t$-test, observed difference was statistically insignificant.

epsilon-aminocaproic acid, and tranexamic acid (TXA) [4]. Among them, TXA has gained the maximum attention which can be given intravenous or intra-articular during the surgery [4]. The available evidence on the selection of more appropriate route of administration of TXA bears controversy. Moreover, present study was also necessitated by non-availability of locally published such material.

In the present study, we observed that the mean age of patients was $67.3 \pm 8.2$ years. Khan et al. [30] reported similar mean age of $64 \pm 6.3$ years in patients undergoing total knee replacement at Ghurki Trust Teaching Hospital Lahore while Obaid-ur-Rahman et al. [31] reported it to be $64 \pm 8.4$ years in such patients at Combined Military Hospital, Rawalpindi. A similar mean age of $67 \pm 7.96$ years has been reported by Maniar et al. [25] in Indian such patients while Pinsornsak et al. [16] reported it to be $67.63 \pm 7.96$ years in Thailand. Keyhani et al. [14] and Sarzaeem et al. [27] reported comparable mean age of $67 \pm 11.9$ years and $67.5 \pm 7.6$ years in Iran while Seo et al. [23] reported it to be $67.5 \pm 6.6$ years in Korea.

We observed a female predominance in patients undergoing TKR with a male-to-female ratio of 1:3.7. A similar female predominance among TKR patients has been reported by Chen et al. [11] in Singapore who reported a male-to-female ratio of 1:4. Digas et al. [22] and Drosos et al. [12] reported similar female predominance with male-to-female ratio of $1: 3.3$ and 1:4 respectively in Greece. Pinsornsak et al. [16] reported much higher female predominance with male-to-female ratio of 1:5 while Aggarwal et al. [21] reported a male predominance (m:f, 1.9:1) in India.

In the present study, we observed insignificant difference between intra-articular and intra-venous tranexamic acid in terms of mean post-operative hemoglobin and hematocrit and mean fall in hemoglobin and hematocrit. Our results are comparable to those of Digas et al. [22] who also reported similar insignificant difference between IA and IV TXA in terms of mean fall in hemoglobin after TKR $(2.26 \pm 0.99$ vs. $2.24 \pm 0.93 \mathrm{~g} / \mathrm{dL}$; $p$-value $=0.72)$. Similar results have also been published by Soni et al. [18] $(2.21 \pm 0.64$ vs. $2.42 \pm 0.86 \mathrm{~g} / \mathrm{dL} ; p$-value $=0.38)$, Tzatzairis et al. [19] $(2.95 \pm 1.33$ vs. $3.2 \pm 1.29 \mathrm{~g} / \mathrm{dL}$; $p$-value $=0.551)$, Seo et al. [23] $(1.8 \pm 0.8$ vs. $1.6 \pm 0.8 \mathrm{~g} / \mathrm{dL}$; $p$-value $>0.05)$, Patel et al. [9] $(3.42 \pm 1.07$ vs. $3.06 \pm$ $1.02 \mathrm{~g} / \mathrm{dL} ; p$-value $=0.108)$, Pinsornsak et al. [16] $(1.85 \pm 0.95$ vs. $1.87 \pm 1.37 \mathrm{~g} / \mathrm{dL} ; p$-value $=0.840)$ and Sarzaeem et al. [27] (3.9 \pm 1.1 vs. $2.6 \pm 0.9 \mathrm{~g} / \mathrm{dL} ; p$-value $>0.05)$. A similar insignificant difference in the mean post-operative hematocrit between IA and IV TXA has been reported by Aguilera et al. [10] (34.69 \pm 3.42 vs. $34.05 \pm 4.53 \%$; $p$ value $=0.073$ ). No significant difference in terms of mean postoperative hematocrit with IA and IV TXA in patients undergoing TKR has also been reported by Tzatzairis et al. [19] (32.44 \pm 3.33 vs. $30.92 \pm 3.11 \%$; $p$-value $=0.112)$, Drosos et al. [12] $(33.19 \pm 2.97$ vs. $32.41 \pm 5.20 \% ; p$-value $=0.197)$ and Pinsornsak et al. [16] $(31.0 \pm 2.7$ vs. $31.8 \pm 3.4 \%$; $p$-value $=0.352)$.

In local population, this type of study has been conducted for the first time and it supports international research already published on this topic. Fairly larger sample size of 200 cases and randomization of study groups to minimize bias which makes the results of the present study more reliable are strengths of this study. From evidence, intra-articular tranexamic acid preference over intravenous route as intra-articular route has been advocated. It is as efficacious as intravenous route, yet it avoids the inconvenience of IV administration and possibly avoids the complication of intravenous administration of TXA like deep vein thrombosis, myocardial infarction, pulmonary embolism, and cerebrovascular events [32].

A biggest limitation associated with this study was non comparing the effects of intra-venous and intra-articular tranexamic acid on coagulation profile as it can be expected that intra-articular tranexamic acid could not have as much deleterious effects as expected from intravenous administration which would further favor the use of intra-articular route. For future researches, this study is recommended strongly.

\section{Conclusion}

In primary total knee arthroplasty, to reduce blood loss, intraarticular administration of tranexamic acid was found to be as effective and safe as intra-venous administration. Due to convenience, the use of intra-articular administration of tranexamic acid after primary TKA may be considered in future practice.

\section{Conflict of interest}

The authors declare that they have no conflict of interest.

\section{Contribution of authors}

Muhammad Khurram Habib: Collection of data, research work and paper writing. 
Prof. Suhail Amin: Chief surgeon who performed all procedures and reviewed and guided about this article.

Aziz Khan Niazi: Data collection.

\section{References}

1. Reinhardt KR, Osoria H, Nam D, Alexiades MA, Figgie MP, Su EP (2013) Reducing blood loss after total knee replacement: a fibrin solution. Bone Joint J 95(11), 135-139.

2. Park JH, Choi SW, Shin EH, Park MH, Kim MK (2017) The optimal protocol to reduce blood loss and blood transfusion after unilateral total knee replacement: Low-dose IA-TXA plus 30-min drain clamping versus drainage clamping for the first $3 \mathrm{~h}$ without IA-TXA. J Orthop Surg (Hong Kong) 25(3), 2309499017731626.

3. Sahu S, Hemlata VermaA (2014) Adverse events related to blood transfusion. Indian J Anaesth 58(5), 543-551.

4. Danninger T, Memtsoudis SG (2015) Tranexamic acid and orthopedic surgery-the search for the holy grail of blood conservation. Ann Translat Med 3(6), 77.

5. Pabinger I, Fries D, Schöchl H, Streif W, Toller W (2017) Tranexamic acid for treatment and prophylaxis of bleeding and hyperfibrinolysis. Wien Klin Wochenschr 129(9), 303-316.

6. May JH, Rieser GR, Williams CG, Markert RJ, Bauman RD, Lawless MW (2016) The assessment of blood loss during total knee arthroplasty when comparing intravenous versus intracapsular administration of tranexamic acid. J Arthroplasty 31(11), 2452-2457.

7. Stowers MDJ, Aoina J, Vane A, Poutawera V, Hill AG, Munro JT (2017) Tranexamic acid in knee surgery study-a multicentered, randomized, controlled trial. J Arthroplasty 32(11), 3379-3384.

8. Goyal N, Chen DB, Harris IA, Rowden NJ, Kirsh G, MacDessi SJ, et al. (2017) Intravenous vs intra-articular tranexamic acid in total knee arthroplasty: a randomized, double-blind trial. J Arthroplasty 32(1), 28-32.

9. Patel JN, Spanyer JM, Smith LS, Huang J, Yakkanti MR, Malkani AL, et al. (2014) Comparison of intravenous versus topical tranexamic acid in total knee arthroplasty: a prospective randomized study. J Arthroplasty 29(8), 1528-1531.

10. Aguilera X, Martínez-Zapata MJ, Hinarejos P, Jordán M, Leal J, González JC, et al. (2015) Topical and intravenous tranexamic acid reduce blood loss compared to routine hemostasis in total knee arthroplasty: a multicenter, randomized, controlled trial. Arch Orthop Trauma Surg 135(7), 1017-1025.

11. Chen JY, Chin PL, Moo IH, Pang HN, Tay DK, Chia SL, et al. (2016) Intravenous versus intra-articular tranexamic acid in total knee arthroplasty: a double-blinded randomised controlled noninferiority trial. Knee 23(1), 152-156.

12. Drosos GI, Ververidis A, Valkanis C, Tripsianis G, Stavroulakis E, Vogiatzaki T, et al. (2016) A randomized comparative study of topical versus intravenous tranexamic acid administration in enhanced recovery after surgery (ERAS) total knee replacement. J Orthop 13(3), 127-131.

13. Gomez-Barrena E, Ortega-Andreu M, Padilla-Eguiluz NG, Pérez-Chrzanowska H, Figueredo-Zalve R (2014) Topical intra-articular compared with intravenous tranexamic acid to reduce blood loss in primary total knee replacement: a doubleblind, randomized, controlled, noninferiority clinical trial. J Bone Joint Surg Am 96(23), 1937-1944.
14. Keyhani S, Esmailiejah AA, Abbasian MR, Safdari F (2016) Which route of tranexamic acid administration is more effective to reduce blood loss following total knee arthroplasty? Arch Bone Jt Surg 4(1), 65-69.

15. Öztaş S, Öztürk A, Akalin Y, Şahin N, Özkan Y, Otuzbir A, et al. (2015) The effect of local and systemic application of tranexamic acid on the amount of blood loss and allogeneic blood transfusion after total knee replacement. Acta Orthop Belg 4, 698-707.

16. Pinsornsak P, Rojanavijitkul S, Chumchuen S (2016) Periarticular tranexamic acid injection in total knee arthroplasty: a randomized controlled trial. BMC Musculoskelet Disord 17, 313.

17. Prakash J, Seon JK, Park YJ, Jin C, Song EK (2017) A randomized control trial to evaluate the effectiveness of intravenous, intra-articular and topical wash regimes of tranexamic acid in primary total knee arthroplasty. J Orthop Surg (Hong Kong) 25(1), 2309499017693529.

18. Soni A, Saini R, Gulati A, Paul R, Bhatty S, Rajoli SR (2014) Comparison between intravenous and intra-articular regimens of tranexamic acid in reducing blood loss during total knee arthroplasty. J Arthroplasty 29(8), 1525-1527.

19. Tzatzairis TK, Drosos GI, Kotsios SE, Ververidis AN, Vogiatzaki TD, Kazakos KI, et al. (2016) Intravenous vs topical tranexamic acid in total knee arthroplasty without tourniquet application: a randomized controlled study. J Arthroplasty 31(11), 2465-2470.

20. Uğurlu M, Aksekili MA, Çalar C, Yüksel K, Şahin E, Akyol M, et al. (2017) Effect of topical and intravenously applied tranexamic acid compared to control group on bleeding in primary unilateral total knee arthroplasty. J Knee Surg 30(2), $152-157$.

21. Aggarwal AK, Singh N, Sudesh P (2016) Topical vs. intravenous tranexamic acid in reducing blood loss after bilateral total knee arthroplasty: a prospective study. J Arthroplasty 31(7), 1442-1448.

22. Digas G, Koutsogiannis I, Meletiadis G, Karamoulas V, Bikos Ch (2015) Intra-articular injection of tranexamic acid reduce blood loss in cemented total knee arthroplasty. Eur J Orthop Surg Traumatol 25(7), 1181-1188.

23. Seo JG, Moon YW, Park SH, Kim SM, Ko KR (2013) The comparative efficacies of intra-articular and IV tranexamic acid for reducing blood loss during total knee arthroplasty. Knee Surg Sports Traumatol Arthrosc 21(8), 1869-1874.

24. Wang J, Wang Q, Zhang X, Wang Q (2017) Intraarticular application is more effective than intravenous application of tranexamic acid in total knee arthroplasty: a prospective randomized controlled trial. J Arthroplasty 32(11), 3385-3389.

25. Maniar RN, Kumar G, Singhi T, Nayak RM, Maniar PR (2012) Most effective regimen of tranexamic acid in knee arthroplasty: a prospective randomized controlled study in 240 patients. Clin Orthop Relat Res 470(9), 2605-2612.

26. Lacko M, Cellar R, Schreierova D, Vasko G (2017) Comparison of intravenous and intra-articular tranexamic acid in reducing blood loss in primary total knee replacement. Eklem Hastalik Cerrahisi 28(2), 64-71.

27. Sarzaeem MM, Razi M, Kazemian G, Moghaddam ME, Rasi AM, Karimi M (2014) Comparing efficacy of three methods of tranexamic acid administration in reducing hemoglobin drop following total knee arthroplasty. J Arthroplasty 29(8), 15211524. 
28. Triyudanto AN, Lubis AM (2017) The effects of intra-articular tranexamic acid given intraoperatively and intravenous tranexamic acid given preoperatively on post surgical bleeding and transfusion rate post total knee arthroplasty. Med J Indonesia 25(4), 234-239.

29. Numkanisorn S, Chareancholvanich K, Pornrattanamaneewong C (2016) Intravenous tranexamic acid before and after tourniquet use can reduce blood loss and blood transfusion after total knee arthroplasty. J Med Assoc Thai 99(11), 1220-1225.

30. Khan M, Ahmed A, Umer F, Zaman AtiqUz, Ahmad S, Ahmed N, et al. (2017) Total knee arthroplasty; postoperative mean blood loss with tranexamic acid, is tranexamic acid effective in reducing blood loss. A randomized controlled trial in tertiary care hospital, Pakistan. Prof Med J 24(7), 992-996.

31. Obaid-ur-Rahman HafeezS, Amin MS, Syed HM, Shah WA, Talha M, et al. (2014) Preventing the preventable: role of transamine in total knee arthroplasty. J Pak Med Assoc 64(12), S44-S48.

32. Danninger T, Memtsoudis SG (2015) Tranexamic acid and orthopedic surgery - the search for the holy grail of blood conservation. Ann Translat Med 3(6), 77.

Cite this article as: Amin MS, Habib KM \& Rehman AU (2020) Comparison of blood loss between intra-articular and intra-venous administration of tranexamic acid in primary total knee arthroplasty. SICOT-J 6, 20 